\title{
ENERGY SIMULATION SUPPORTED SKETCH PLAN OPTIMIZATION OF THE UNIVERSITY OF PÉCS, MEDICAL SCHOOL EXTENSION
}

\author{
${ }^{1}$ Dóra Noémi ZETZ ${ }^{*}{ }^{2}$ István KISTELEGDI \\ ${ }^{1}$ Breuer Marcel Doctoral School, Department of Building Structures and Energy Design \\ Institute of Architecture, Faculty of Engineering and Information Technology \\ Boszorkány u. 2, University of Pécs, H-7624 Pécs, Hungary, e-mail: ${ }^{1}$ zetzdora@gmail.com \\ ${ }^{2}$ Department of Building Structures and Energy Design, Institute of Architecture \\ Faculty of Engineering and Information Technology, Boszorkány u. 2 \\ and János Szentágothai Research Center, Ifjúság u. 20, University of Pécs \\ H-7624 Pécs, Hungary, e-mail: ${ }^{2}$ kistelegdisoma@mik.pte.hu
}

Received 30 May 2019; accepted 22 November 2019

\begin{abstract}
A building physics supported development was undertaken for the new block of the University of Pécs, Medical School. During sketch design stage climate, lighting and energy simulations were applied to quantify energy optimization strategies. Simulation cases assess the impact of shading technologies, wall-window ratios and thermal masses on used thermal energy demand. Based on a previous study about visual and comfort performance, goal was to identify the highest energy efficiency rates with maximum investment cost savings. Besides best comfort results, the most optimal development represents $9 \%$ saving in used thermal energy, and they were proposed for further design.
\end{abstract}

Keywords: Medical school, Sketch plan optimization, Shading, Wall-window ratio, Thermal mass, Energy demand, Energy efficiency, Optimal model

\section{Introduction and research goal}

The Energy Design Research Group at University of Pecs conducts thermal dynamic and light simulation studies for optimal building design. Simulation works as a decision support system for analyzing alternatives of building geometry, building structures, building services systems, comfort and energy. In the framework of the simulation design part, the concept suggestions are tested in building physics, building climate and energy modeling, dynamic calculations and the results serve as basis for understanding and analyzing the variants and then making the concrete design recommendations.

\footnotetext{
${ }^{*}$ Corresponding Author
} 
Particular study deals with an office and lab building optimization. A great number of research papers explore solutions and strategies in building energy optimization, with special focus on building envelope, building geometry and shape, energy systems [1][8]. Besides sophisticated and systematic analysis of the passive and active design solutions, most research studies assess theoretical and general building energy optimization issues, without any linkage to feedback from real implemented buildings or measurements. In contrast, this research project is the embedded second stage of the University of Pécs, Medical School extension design procedure, to be implemented in 2019. The examined building possesses 5 levels with a total of approx. $12.916 \mathrm{~m}^{2}$ useful floor area. The typical boundary conditions for building optimization were fixed space organisation, functional layout, building body shape and structures, materials, defined by the architect [9] and the contractor. After preliminary comfort tests, energy simulation studies became necessary for decision support of the outline plan [10]. Prior dynamic thermal building simulations of prototype public building projects [11] enabled to gain a broad understanding and experience in hig-tech simulation modeling, as well as calculation accuracy. In the energy simulation tests, diverse shading, wall-window ratio (WWR), and thermal mass design variations were analyzed and the optimal ones were selected. The building envelope represents one of the main energy and comfort influencing design factor in both complex theoretical building optimization investigation domains as well as in real implementation building design optimization projects. This interesting coincidence underlines the building envelope's crucial and decisive role in office building comfort and energy performance. Fig. 1 displays the new building block of the University of Pécs, Medical School.
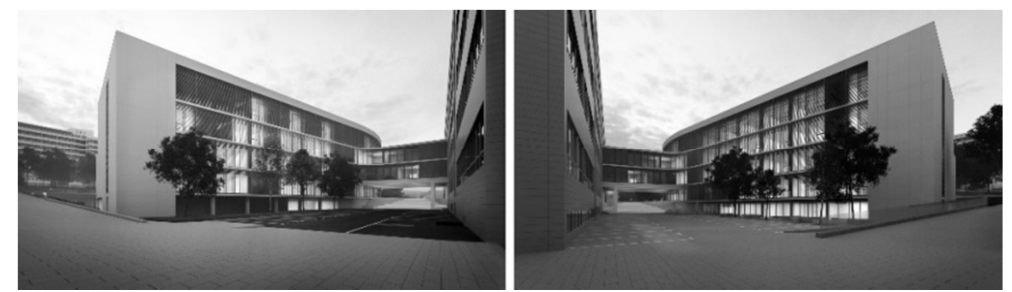

Fig. 1. Rendering 3D perspective view of the new block of the University of Pécs, Medical School

\section{Methodology}

Used energy demand surveys were conducted with thermal building simulations using IDA ICE software, taking into account building configuration, neighborhood and orientation to determine the following structures, as it is elaborated in the previous comfort investigation study [10]:

- the need for different shading technologies;

- investigation of diverse facades with accordingly alternating WWR;

- the effect of releasing heat storage masses (abandonment suspended ceiling). 
In all cases the used energy demand was examined during both heating and cooling operation periods by taking solar gains in winter, and radiation loads in summer into account.

\section{Results and discussion (Case studies)}

The cases shown in Table I have already been investigated [10] at thermal and visual comfort performance, hence actual energy consumption cases have been analyzed against the reference Model 1. The Model 2 - Model 5 tests contain different shading solutions, while Model 6 - Model 8 possess various Parapet Heights (PH), as well as different WWR. In case of Model 9, the effect of the heat storage mass released by abandonement of the suspended ceilings was examined.

\section{Table I}

Settings and properties of various models in the investigated cases

\begin{tabular}{|c|c|c|c|c|c|}
\hline \multicolumn{2}{|c|}{ Model descript. } & Shading type & PH & WWR & SC \\
\hline $\begin{array}{c}\text { Model } \\
1\end{array}$ & Reference & $75 \mathrm{~cm}$ cantilever per level & - & $\begin{array}{c}\text { Sample } 95 \% \text {, Total } \\
20.9 \%\end{array}$ & yes \\
\hline $\begin{array}{l}\text { Model } \\
2\end{array}$ & \multirow{4}{*}{$\begin{array}{l}\text { Shading } \\
\text { tech. } \\
\text { variants }\end{array}$} & $165 \mathrm{~cm}$ cantilever per level & - & $\begin{array}{c}\text { Sample } 95 \% \text {, Total } \\
20.9 \%\end{array}$ & yes \\
\hline $\begin{array}{l}\text { Model } \\
3\end{array}$ & & $\begin{array}{l}\text { solar controlled external } \\
\text { blinds }\end{array}$ & - & $\begin{array}{c}\text { Sample } 95 \% \text {, Total } \\
20.9 \%\end{array}$ & yes \\
\hline $\begin{array}{c}\text { Model } \\
4\end{array}$ & & $\begin{array}{l}\text { external fixed vertical } \\
\text { louver-boards - all year }\end{array}$ & - & $\begin{array}{c}\text { Sample } 95 \% \text {, Total } \\
20.9 \%\end{array}$ & yes \\
\hline $\begin{array}{l}\text { Model } \\
5\end{array}$ & & $\begin{array}{l}\text { external fixed horizontal } \\
\text { louver-boards - all year }\end{array}$ & - & $\begin{array}{c}\text { Sample } 95 \% \text {, Total } \\
20.9 \%\end{array}$ & yes \\
\hline $\begin{array}{l}\text { Model } \\
6\end{array}$ & \multirow{3}{*}{$\begin{array}{c}\text { WWR } \\
\text { variants }\end{array}$} & $75 \mathrm{~cm}$ cantilever per level & $\begin{array}{l}60 \\
\mathrm{~cm}\end{array}$ & $\begin{array}{c}\text { Sample } 76 \% \text {, Total } \\
18,3 \%\end{array}$ & yes \\
\hline $\begin{array}{l}\text { Model } \\
7\end{array}$ & & $75 \mathrm{~cm}$ cantilever per level & $\begin{array}{l}90 \\
\mathrm{~cm}\end{array}$ & $\begin{array}{c}\text { Sample } 66,5 \% \text {, Total } \\
17 \%\end{array}$ & yes \\
\hline $\begin{array}{l}\text { Model } \\
8\end{array}$ & & $75 \mathrm{~cm}$ cantilever per level & $\begin{array}{l}120 \\
\mathrm{~cm}\end{array}$ & $\begin{array}{c}\text { Sample } 57 \% \text {, Total } \\
15,7 \%\end{array}$ & yes \\
\hline $\begin{array}{l}\text { Model } \\
9\end{array}$ & $\begin{array}{c}\text { 'Active' } \\
\text { heat } \\
\text { storage }\end{array}$ & $75 \mathrm{~cm}$ cantilever per level & - & Total $20.9 \%$ & no \\
\hline
\end{tabular}

Main purpose of the model case investigations originally were to test different shading solutions in the fully glazed main facades of the new building block. The best shading, meaning thermal comfort results were performed by model 5 , the external fixed hotizontal louvre-boards structure solution. Furthermore, various WWR models examined 60,90 and $120 \mathrm{~cm}$ high parapet wall structures, which appropriately reduced the glazing ratio from $95 \%$ (fully glazed façade) to $57 \%$ WWR (120 cm high parapet façade version). The less glazing proportion is planned in the façade, the higher number 
of thermal comfort occupancy hours in thermal comfort category I (A) and II (B) according to EN 15251 and ISO 7730. A last case study quantifed the thermal comfort performance of a model without suspended ceiling structures in the spaces. This solution was able to further improve the number of the class I (A) and II (B) comfort hours, as the activation of the thermal mass in the reinforced concrete slabs acts as an effective internal passive cooling 'device'. The visual comfort was examined through assessment of the number of occupancy hours with daylight illumination intensity above $500 \mathrm{~lx}$. The more effective various shading versions worked, the more decrease of daylight intensity was achieved. This effect was similar in the desreasing WWR models as well. However, the reduction of the visual comfort hours does not negatively effect the daylight situation in the offices, since in this building use today's Information Technology (IT) does not require high daylight level in the spaces. Moreover, less illuminantion (but min. $500 \mathrm{~lx}$ ) can even cause higher visual comfort sensation with improved thermal comfort effects. After the thermal and visual comfort assessments, cardinal question is how these modes behave in terms of energy efficiency.

\subsection{Used energy demand - all façade connected rooms}

Different shading models have been tested for heating and cooling used energy demand in all façade connected spaces (Fig. 2). It can be clearly seen that the heating energy demand is the dominant scale due to the transmission heat loss caused by the large glazing ratios. Heating demand is growing up to $16 \%$ with increasing shading efficiency. Shading reduces cooling by $37-91 \%$ according to the different shading techniques. Solar controlled external blinds and fixed horizontal louvres perform the most cooling conservation. However, on the level of total heating and cooling, the difference in total energy demand is max. $5 \%$, therefore shading is not recommended.

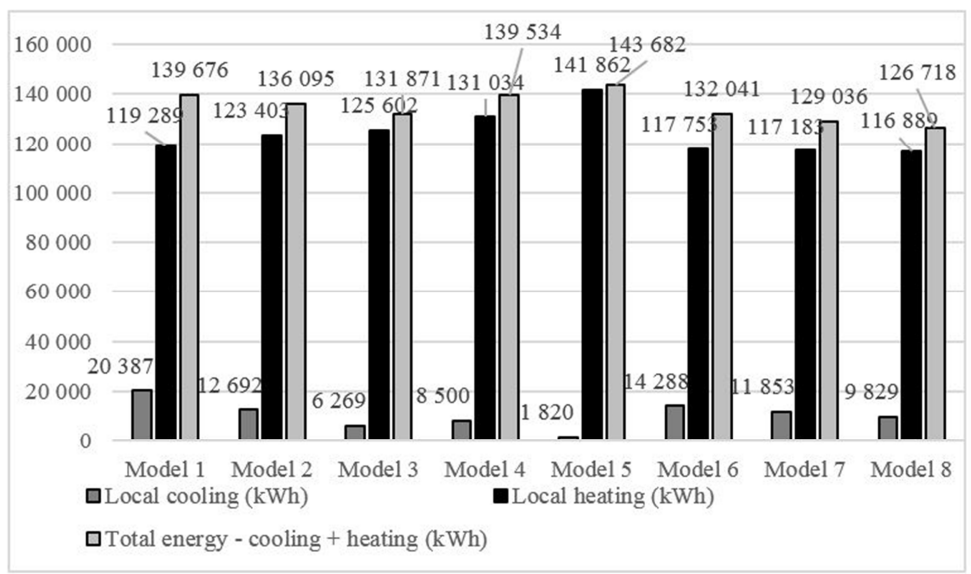

Fig. 2. Used energy demand in all façade connected rooms, kWh/a, (IDA ICE 4.8)

Fig. 2 shows the heating and cooling energy requirements of the models with three different WWR in façade connected rooms (Model 6 - Model 7). It can be observed that 
Model 6 provides $30 \%$, Model $742 \%$ and Model $852 \%$ cooling energy savings compared to the reference case. There was also a decrease in the heating energy demand, but its rate is minimal, due to the compensation effect between less heat loss and less solar gains with decreasing WWR. In total cooling and heating max. 9\% savings is possible at room level.

\subsection{Used energy demand - complete building}

Fig. 3 demonstrate the used energy demand for the whole building, where the cooling energy requirement is already decisive because of the function of the building (office, lab with high thermal loads) and the large number of internal closed rooms. Shading has no impact on total heating and cooling demand, as the large-scale building complex $\left(12916 \mathrm{~m}^{2}\right)$ has a great number of interior spaces (approx. $40 \%$ of the total floor area) and the north oriented spaces (approx. 20\% of the net floor area) are less influenced by the shading. In the energy performance of the complete building, the low cooling savings (6-10\%) and heating increase (3-10\%) compensate each other, therefore energetically the use of expensive external weatherproof shading is not economic. The plus on cooling demand means a much lower energy demand and environmental damage Life-Cycle Analysis (LCA) than the production and purchase of shading structures.

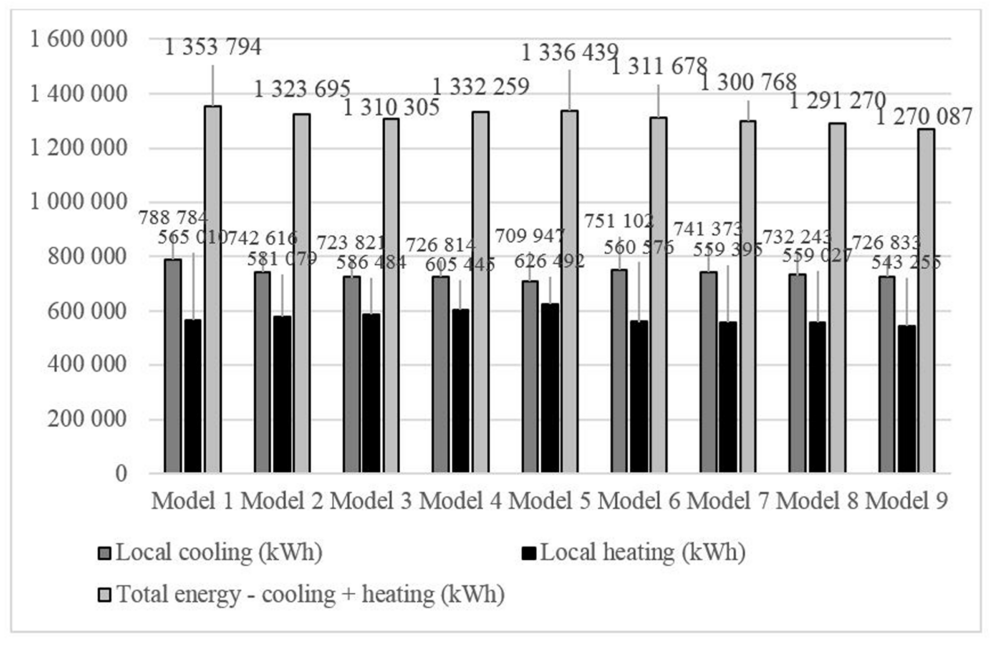

Fig. 3. Used energy demand in the complete building, kWh/a, (IDA ICE 4.8)

Regarding wall-window ratio, the cooling energy demand is decisive too. Based on similar reasons as in the shading study, the glazing ratio has little effect on the total heat demand. The cooling savings are $5-7 \%$, heating conservations are $1 \%$, and in total max. $5 \%$ reduction is achieved. Despite the low savings, it is advisable to use parapets, due to high construction an LCA and Life-Cycle Cost Analysis (LCCA) savings in the façades (reduction of glazing ratio). Best results are gained in the $120 \mathrm{~cm}$ high parapet design, 
although the $90 \mathrm{~cm}$ high parapet version seems more realistic considering the implementation and architectural aspects, so this solution can be recommended as an optimal compromise.

The test of 'activating' heat storage mass has a decisive effect on the whole building, so the evaluation focusses on that scale. With leaving the suspended ceiling the dominant cooling energy demand could be decreased by approx. $8 \%$, the heating energy demand by approx. $4 \%$, while the overall (heating + cooling) saving reached approx. $6 \%$. This saving is already at the threshold value of energy efficiency in case of large sized buildings, coupled with improved life cycle assessment, $\mathrm{CO}_{2}$-balance, furthermore achievable significant investment cost reductions. For these reasons, it may be advisable to abandon suspended ceilings in further design steps. If the design of the Heating, Ventilation, and Air Conditioning (HVAC) system requires optical coverage in the rooms, it is recommended to design it only locally (e.g. strip-like solution alongside the windows), leaving the slab surface free, or possibly using a perforated, mesh-like 'optical' ceiling, which only partly blocks the beneficial energy and comfort effects of heat storage slabs.

\subsection{Optimal building envelopre model proposal}

Considering the results of the introduced energy case investigations, an optimal combination was proposed to achieve highest energy efficiency perfomance. The Model 10 version was developed within the projects design boundaries, proposing no shading devices, exclusion of suspended ceiling and $90 \mathrm{~cm}$ height of parapet structures. The decision of this combination is based on the following:

- shading has no considerable impact on used thermal energy demand, due to the intensive shielding effect of the southern existing Medical School block;

- the abandonment of the suspended ceiling enable the reduction of heating and cooling used energy demand due to the advantageous self-regulation effect of the internal thermal mass of the reinforced concrete slab structures;

- by reducing the WWR, the cooling energy demand can be significantly lowered, while according to achitectural and functional reasons the medium sized, $90 \mathrm{~cm}$ high parapet version is proposed.

The analysis results of the optimal model (Model 10), were compared with the results of the reference model (Model 1). Model settings and properties are illustrated in Table II.

Table II

Settings and properties of the reference and the optimal model cases

\begin{tabular}{|c|c|c|c|c|c|}
\hline \multicolumn{2}{|c|}{ Model descript. } & Shading type & PH & WWR & SC \\
\hline $\begin{array}{c}\text { Model } \\
1\end{array}$ & Reference & $75 \mathrm{~cm}$ cantilever per level & - & $\begin{array}{c}\text { Sample } 95 \%, \text { Total } \\
20.9 \%\end{array}$ & yes \\
\hline $\begin{array}{c}\text { Model } \\
10\end{array}$ & $\begin{array}{c}\text { optimal } \\
\text { model }\end{array}$ & $75 \mathrm{~cm}$ cantilever per level & 90 & $\begin{array}{c}\text { Sample } 66,5 \%, \text { Total } \\
17 \%\end{array}$ & no \\
\hline
\end{tabular}


In all façade rooms $70 \%$ of cooling energy savings were achieved, due to the beneficial effect of the thermal mass and the $90 \mathrm{~cm}$ high parapet (30\% less WWR). Heating conservation accounts for $4 \%$ per year. The lower rate of winter savings is based on the 3-layer glazing's good thermal properties (the resulting relatively lower heat loss) and the less winter solar gain reduced by the parapet. In total (heating + cooling) the savings rise to $14 \%$ (the highest improvement among all cases) (Fig. 4).

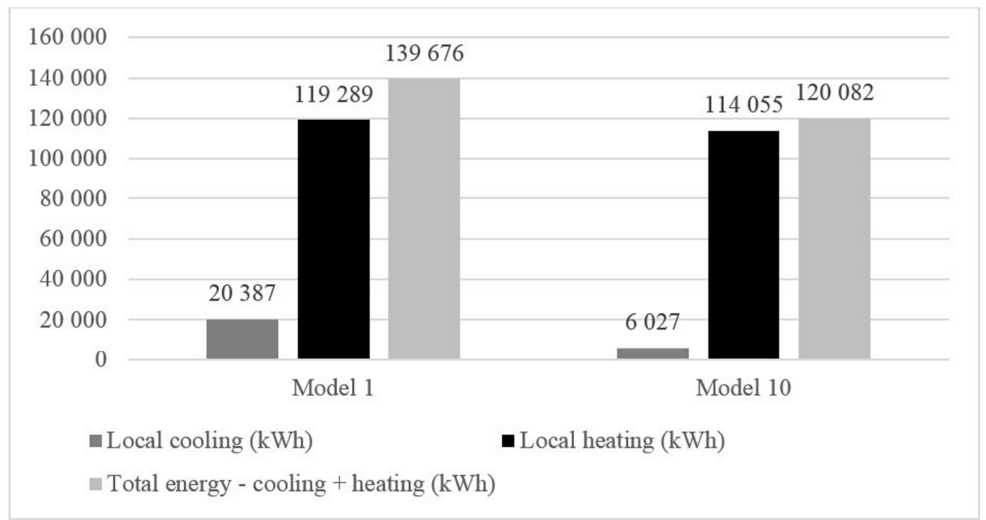

Fig. 4. Used energy demand in all façade connected rooms, kWh/a, (IDA ICE 4.8)

In the complete building $11 \%$ cooling and $4 \%$ heating energy savings appears in a year. Cooling reduction decreased due to the high ratio of internal spaces and north oriented rooms. The overall $8.35 \%$ savings - the largest case so far - could be finally achieved (Fig. 5).

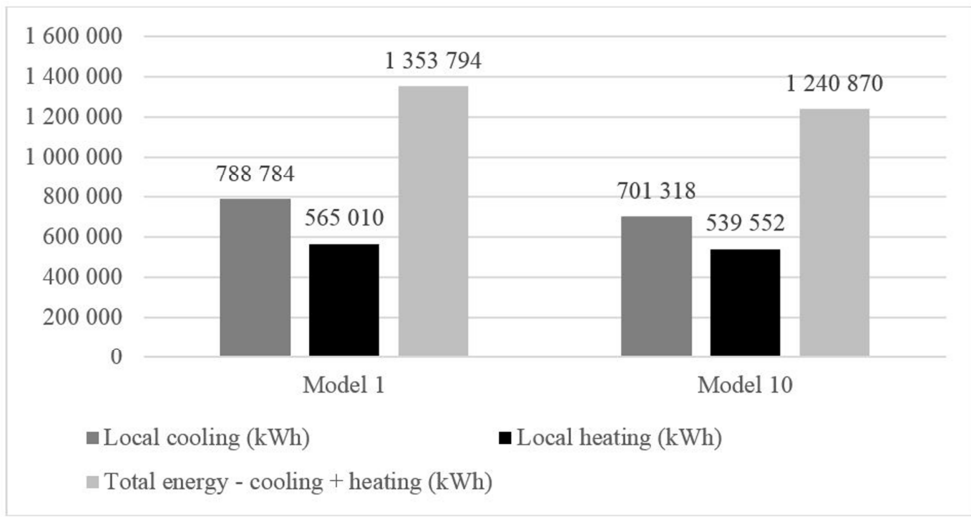

Fig. 5. Used energy demand in the complete building, kWh/a, (IDA ICE 4.8) 


\section{Conclusions}

Previous experiences in simulation validation of office, indusrty as well as residential experimental reference buildings proved over $90 \%$ accuracy of the dynamic thermal simulation tecnology (agreement between calculation and measurement results), applied in particular study. Results of 10 optimisation model versions revealed that in aforementioned office/lab design process external shading delivers used cooling energy savings only in spaces adjacent to east-south-west facades, while heating demand raises. For the complete building, external shading technologies are inefficient due to offset of solar loads and gains. In the previous study of this project the thermal comfort is slightly increased but can be easily compensated by using renewable energies in combination of efficient cooling HVAC technology. The reduction of the WWR from 95 to $57 \%$ brought also little thermal comfort enhancement, while the used thermal energy demand reached $5 \%$ conservation rate, a threshold value to be considered in building operation costs of this kind of large scaled public buildings $\left(12,916 \mathrm{~m}^{2}\right)$. While expensive and LCA intensive shading devices are inefficient, the reduction of the WWR saves operation, investment and LCA, as well as LCCA costs. Thermal mass application performs similar effect in thermal comfort improvement as in the best shading case, with approx. $6 \%$ used thermal energy demand reduction.

As an optimum combination, the architecturally acceptable (contractor's and architect's preference) WWR of $66.5 \%$ (90 cm parapet) and the thermal mass application (abandonment of the suspended ceilings) could be proposed. Besides increase of thermal comfort hours $11 \%$ cooling and $4 \%$ heating energy savings (total of $8.35 \%$ thermal used energy reduction) were achieved in the entire building per year. This can be reported in annually approx. $112,880 \mathrm{kWh} / \mathrm{a}$ and $41.2 \mathrm{t} / \mathrm{a} \mathrm{CO}_{2}$-emissions, and approx. 14,000 $€(4,760,000 \mathrm{HUF})$ operating cost reduction. In addition, this solution ensures significant, approx. 300,000 € (102,000,000 HUF) investment savings, further, the LCA impact and $\mathrm{CO}_{2}$-emissions are significantly lower due to the reduction of glazing.

The energy results of the simulation investigations showed that near-by neighborhood structures at south-side of the partcular new building development can provide an intensive shading protection that permits the abandonment of the complete external shading device system. Additionally, it can be stated, that within the framework of the above described boundary conditions, the use of external shading is overwritten by reduction of WWR by approx. 50-70\%, and the use of available structures' thermal mass. Besides operation energy and cost considerations, investment costs, LCA and LCCA play key role as well, whereby WWR reduction and exclusion of external shading are advantageous decisions. Important to emphasize that each design project possess unique shading and radiation circumstances, hence simulations mean always an adequate solution for proving design concepts. Within this 'narrow' design scope further optimisation possibilities occur for HVAC systems and operation control strategies in future approval and construction planning stages of such projects. 


\section{Acknowledgements}

This research was carried out in the Energy Design Research Group, supported by the János Szentágothai Research Centre, University of Pécs.

\section{Open Access statement}

This is an open-access article distributed under the terms of the Creative Commons Attribution 4.0 International License (https://creativecommons.org/licenses/by/4.0/), which permits unrestricted use, distribution, and reproduction in any medium, provided the original author and source are credited, a link to the CC License is provided, and changes - if any - are indicated. (SID_1)

\section{References}

[1] Zhou J., Nazi W. I. W M., Wang Y., Roskilly A. Investigating the impact of building's facade on the building's energy performance - a case study, Energy Procedia, Vol. 158, 2019, pp. 3144-3151.

[2] Farshid Shadram, Jani Mukkavaara, Exploring the effects of several energy efficiency measures on the embodied/operational energy trade-off: A case study of Swedish residential buildings, Energy and Buildings, Vol. 183, 2019, pp. 283-296.

[3] Kirimtat A., Krejcar O., Ekici B., Tasgetiren M. F. Multi-objective energy and daylight optimization of amorphous shading devices in buildings, Solar Energy, Vol. 185, 2019, pp. 100-111.

[4] Krstić-Furundžić A., Vujošević M., Petrovski A. Energy and environmental performance of the office building facade scenarios, Energy, Vol. 183, 2019, pp. 437-447.

[5] Waibela C., Evins R., Carmeliet J. Co-simulation and optimization of building geometry and multi-energy systems: Interdependencies in energy supply, energy demand and solar potentials, Applied Energy, Vol. 242, 2019, pp. 1661-1682.

[6] Baranyai B., Bachmann B., Kistelegdi I. Simulation-supported design of a Hungarian national sports center, Pollack Periodica, Vol. 11, No. 1, 2016, pp. 113-127.

[7] Mozsonics E., Kistelegdi I. Typological investigation of climate systems and design of multifunctional shading structures for the facade of the Szentágothai Research Center, Pollack Periodica, Vol. 10, No. 1, 2015, pp. 61-70.

[8] Póth B., Kistelegdi I. Energy and climate simulations and management system in the Szentágothai Research Center, Pollack Periodica, Vol. 9, No. 1, 2014, pp. 61-70.

[9] Kádár M. Technical Supervision and Planning Consulting Hungary Ltd, Budapest, 2018.

[10] Zetz D. N., Kistelegdi I. Comfort simulation supported sketch plan optimization of the University of Pécs, Medical School extension, Pollack Periodica, Vol. 15, No. 2, 2020, pp. 166-177.

[11] Kistelegdi I., Baranyai B. Dynamic simulation supported indoor climate and energy building modeling, International Journal of Engineering and Technology, Vol. 5, No. 2, 2013, pp. 181-186. 